\title{
The Impact of Currency Liquidity Excess on Price Volatility in the Future Market
}

\author{
Chen Zhu ${ }^{1}$, Liping Chen ${ }^{2 * *}$ \\ ${ }^{1}$ Business School of Nanjing Normal University \\ ${ }^{2}$ School of Foreign Languages and Cultures, Nanjing Normal University \\ *Corresponding author: chenliping@njnu.edu.cn
}

\begin{abstract}
The main contribution of this paper is to identify the relationship between liquidity excess and futures copper price in developing countries. To this end, we compare various measures of liquidity excess and identify one that can measure the degree of liquidity excess and which is particularly applicable to developing countries like China. Through multiple regression analysis, it is found that liquidity excess accounts for the changes of copper prices in the future market.
\end{abstract}

Keywords: liquidity, excess, futures, copper, prices

Cite This Article: Chen Zhu, and Liping Chen, "The Impact of Currency Liquidity Excess on Price Volatility in the Future Market.” Journal of Finance and Accounting, vol. 5, no. 2 (2017): 31-39. doi: 10.12691/jfa-5-2-1.

\section{Introduction}

In the paper we examine the link between currency liquidity excess and volatility of prices in future market. Currency liquidity is not only an economic issue, but also a monetary phenomenon. Over the past 10 years there is a significant fluctuation of liquidity in the macro monetary economic operation among the major world economies. From 2001 to 2007 there was a significant excess, but towards the end of 2007 when subprime mortgage crisis broke out, the real economy gradually fell into decline and came to a standstill, which contributed to the extreme shortage of liquidity by the end of 2008 . When the world economy recession intensified due to the financial crisis, all the countries adopted a loose monetary policy and active fiscal policy to stimulate the economy, the first half of 2009 witnessing the sudden global liquidity change from shortage to excess, which is particularly prominent in China and other emerging economies. Hence, understanding the effects of currency liquidity on market dynamics has gained an increased attention from regulators, market participants and academics alike.

Many studies have tried to find the relationship between the provision of money and all kinds of financial asset price volatility. For instance, Roger Ferguson [8] focused on the analysis of the impact of changes in the broad monetary aggregates on the stock and real estate price index. However, the results have shown great difference and instability in different asset types. This finding is consistent with the views of many other scholars such as Bruggeman [1], Sebastian [21] and White [25]. One of the reasons for the inconsistence of the findings may lie in the fact that the measures of the liquidity excess adopted in these studies are not so precise and stable.
Besides, most of the studies are based on developed countries up to now. Actually, currency abnormality and volatility of prices are more prominent in emerging economies, which contributes to many economic problems such as inflation, rises in prices in both spot market and future market and so on, so it is more urgent to find out the predictive power of currency provision on macroeconomic operation in developing countries.

In this paper, we propose a measure of excessive liquidity which is more concise and stable, and which is particularly applicable to developing countries like China. Capital liquidity excess is a kind of macro excess liquidity, which is more than the balance of the stock of money supply. The current views about excess liquidity in the academic circles can be mainly divided into two types: one is from the view of bank liquidity [20,22,28], insisting that the more excess reserves commercial banks have, the more excess liquid assets there are in the financial system, the more serious the problems caused by liquidity excess are; the other is from the view of the currency issuing, maintaining that there is an excess in the money supply compared to the development of entity economy. There are many factors involved in the measurement of the liquidity excess, but they can be divided into quantitative index and price index. By means of a brief carding and analysis, we show that M2/GDP is the most suitable measure of liquidity excess for emerging economies like China. In fact, the measure we revised can not only reflect the rough situation of liquidity, but also indicate the degree of liquidity excess. We use the data set of both China and the US from 1999 to 2008 to validate the measure.

In the case study, we apply the measure of liquidity excess to evaluate the predictive power on copper prices in Shanghai Futures Exchange and Hongye Futures Brokerage Company. In order to measure the volatility precisely, we made a log processing of the explanatory 
variables and all of the control variables in advance to improve the model. It is found that the combination of the money supply growth rate, copper inventories and GDP growth rate, the exchange rate of RMB against the U.S. dollar and Shanghai stock composite index can explain $80.7 \%$ of the fluctuations of copper prices.

Finally, we find that liquidity excess is caused by the loose monetary policy adopted by three world largest economies and that the liquidity excess leads all the asset prices to rise, including copper prices in the future market.

This paper relates to the literature that attempts to measure the liquidity excess considering quantitative index and price index. In the case of quantitative index, researchers attempted to calculate the liquidity excess from the perspectives of money gap, money overhang, or M/GDP. For instance, Polleit \& Gerdesmeier [18], calculated the liquidity excess by means of money gap in the euro area. Gouteron \& Szpiro [10], Rueffer \& Stracca [19], Belke et al. [3] used M/GDP index to point out that there existed excess liquidity in the euro zone, the United States, Japan and the United Kingdom. Borio \& Lowe [4] and Gouteron \& Szpiro [10] used the Credit/GDP index besides M/GDP and interest rates to measure the excess liquidity. Similar studies were carried out in China too. For instance, $\mathrm{Xu}$ and Ye [26] applied the monetary excess index in China to calculate the surplus situation from the first quarter of 1997 to the second quarter of 2007. Li [15] also calculated China's a surplus of money from 1978 to 2004 by estimating money demand function. Ha [11], Xia and Chen [5] and Zhang [29] used M / GDP index to study China's excess liquidity. However, most of them just adopt the existing measure models to make the calculation of the liquidity excess without any revision.

This paper is part of the market microstructure literature that examines the predictive power of liquidity on volatility. Baks \& Kramer [2] and Giese \& Tuxen [9] studied the impact of currency liquidity surplus on stock market returns in various countries. Some scholars also tested the impact of Chinese liquidity abnormity on asset prices with empirical studies, concluding that changes in market liquidity is the main reason for the current asset price fluctuations [16]. Based on the VEC, Jin et al. [12], Tian \& Fang [22] and Xu et al. [27] found that continuous rise in asset prices and liquidity excess are an important feature of China's economic operation in recent years, and that liquidity excess and investor behavior are the two important factors of asset price fluctuations by introducing liquidity excess into noise trading model. However, few of these studies made a comprehensive analysis through multivariate regression.

Our main contribution to the literature is threefold. First, we identify a particular measure of liquidity excess which is especially applicable to developing countries. In measuring excess liquidity, we use "money gap" index to calculate the monthly Marshall $\mathrm{K}$ value in the sample period (such as m2 / GDP) and the deviation value of the long-term trend after the HP filter, and then to subtract the statistical average deviation values of all the samples. Thus, the liquidity excess calculated in this way is more concise and stable. Second, we improve the model of calculating volatility by making a log processing of the explanatory variables and all of the control variables in advance. So, AVOLt is on a logarithmic scale in calculation. Third, unlike the former studies, which examine the volatility-liquidity relationship at an individual stock level, we provide further theoretical research and more empirical evidence to prove that the excess liquidity has effects on volatility of prices by means of a comprehensive empirical study.

The rest of the paper is organized as follows. In the next section, we provide a brief analysis of the measurement index of liquidity excess. In Section 3, we introduce a suitable measurement of the liquidity excess for developing countries like China. In Section 4, we apply the measurement to the copper transaction in Shanghai Futures Exchange and Hongye Futures Brokerage Company to evaluate the predictive power on copper prices. The last section is the conclusion.

\section{Analysis of the Measurement Index of Liquidity Excess}

Capital liquidity excess is a kind of macro excess liquidity, which is more than the balance of the stock of money supply. The current measurement methods can be divided into quantitative measure and price measure. The following is a brief carding and analysis of various index involved in calculating liquidity excess before a suitable measurement is identified.

\subsection{Quantitative Index}

In the case of quantitative measure, several indexes are involved like money gap, money overhang and so on. Here is a brief introduction of each of them before making a comparison of their advantages and disadvantages.

\subsubsection{Money Gap}

ECB [6] formally proposed the concept of money gap. The report pointed out that, in addition to the annual growth rate of the currency, liquidity surplus measured by the money gap can provide additional information for the inflation pressure. The monetary gap is the difference between the actual money supply and the balance of money supply. There are two ways to get the value of money supply, based on the transaction equation and the money demand equation. The former is more widely used than the latter.

The currency gap can be divided into the nominal money gap and the real money gap. In the case of the nominal money gap, the European Central Bank [6] offered a simple example with the calculation method. They used the last quarter of 1998 as the base year, and got $2 \%$ for the stable price growth rate, $2 \%-2.5 \%$ for the potential output growth rate, $0.5 \%-1 \%$ for the velocity decline rate, $4.5 \%-5.5 \%$ for the stable growth rate. According to the money supply actual value of the last quarter of 1998, the reference value of the money supply of each period after that was calculated. The difference between real money stock and the value of the money supply reference value is the nominal currency gap. Compared with the nominal money gap, the real money gap is slightly more complex. Both the actual money 
supply and the money supply reference value should be used in the actual CPI price index to be reduced before getting the difference. The difference between the nominal money gap and the real money gap lies in the fact that the real money gap eliminates the effect of the actual price on the equilibrium price deviation. When the real inflation rate exceeds the equilibrium inflation rate, the nominal money gap is higher than the real money gap.

Following the ECB's method, scholars made various studies on the currency gap. Polleit \& Gerdesmeier [18] calculated euro area currency liquidity surplus from December 1998 to October 2004 and found that liquidity problems are very serious in the euro area since 1998, where the nominal currency gap was as high as $10 \%$ in late 2004, and the real money gap was as high as $6 \%$. They calculated money gap by calculating the equilibrium value of currencies, the second method. They firstly obtained the previous currency demand function before the establishment of the euro zone, and then used longterm equilibrium output and long-term equilibrium interest rates to calculate the real money gap in the region from the first quarter of 1980 to the fourth quarter of 1998.

\subsubsection{Money Excess}

ECB [6] pointed out that money excess can also be interpreted in terms of money demand. From this perspective, money excess refers to the money supply more than money demand. In fact, the difference between money excess and money gap lies in the different definitions of the value of equilibrium currency. In the definition of monetary excess, the value of equilibrium currency is the estimated value of long-term money demand, which has not considered the deviation from the actual output to the potential output and the deviation from the actual price level to the equilibrium price level. However, in the case of money gap, the equilibrium currency value is the estimated value consistent with the price stability and the potential output, ignoring the current actual value of the two variables. Generally speaking, the residual term in the money demand function is money excess. As the information included in the money excess index is little, few of the existing literature calculated excess money in this way, and even fewer literature used it to conduct empirical research. Xu and Ye [26] applied the monetary excess index in China to calculate the surplus situation from the first quarter of 1997 to the second quarter of 2007. Li [15] also calculated China's a surplus of money from 1978 to 2004 by estimating money demand function.

\subsubsection{M/GDP}

M/GDP index can be used to measure the excess liquidity because it provides information about the total amount of money relative to the economy. $\mathrm{M}$ here refers to the money supply, the broad money supply. M/GDP index is more common in the empirical literature, but there are relatively few theoretical discussions. Specifically, the index is subdivided into three kinds, that is, the horizontal value, the dynamic growth rate of the logarithm, and the deviation from the trend value. The application of the horizontal value can be found in the literature like Gouteron \& Szpiro [10], Rueffer \& Stracca [19], Belke et al. [3], Xia and Chen [5] and Zhang [29], to study the impact of liquidity excess on various economic factors, such as asset prices, housing prices, global currency liquidity and so on.

$\mathrm{M} / \mathrm{GDP}$ dynamic growth rate after the logarithm is the money supply growth rate minus the nominal GDP growth rate. Under the assumption that the velocity of money is constant, the money supply that exceeds the nominal GDP growth rate is called the excess money supply, which is believed to be money liquidity excess by a lot of researchers. Baks \& Kramer [2] studied the impact of currency liquidity surplus on stock market returns from the first quarter of 1971 to the fourth quarter of 1998 in G7 countries. Giese \& Tuxen [9] also used this index to represent the liquidity excess in the cointegrated var system to study the relationship between monetary policy and asset prices in the six countries like France, Germany, Britain, Japan, Italy and the United States. Bank (2007) did a rough estimate of the global liquidity surplus since 1996 by means of this index.

Some researchers used M/GDP and its long-term trend of deviation to calculate the degree of excess liquidity. The first step in this method is to find out the long-term trend of the ratio, and then compare the actual value with the trend value of M/GDP. If the actual value exceeds the trend value, it can be considered that there is a surplus of money. There are two kinds of methods in the application of M/GDP to calculate the long term trend. One is the deterministic time trend, and the other is the HP filter. Bruggeman [1] used M/GDP and its HP filter as a measure of the value of the excess of money to deal with 18 industrialized countries. Ha [11] used M / GDP and trend value of the positive deviation to illustrate that monetary liquidity excess is obvious in developed countries like the United States, the euro area and Japan since 2000, but he did not mention the method of getting the value of the trend. Belke et al. [3] used M/GDP index to point out that there existed excess liquidity in the relevant countries, and at the same time they also used the absolute value of the currency and the long-term trend of the positive deviation to strengthen their judgments.

\subsubsection{Credit/GDP}

Credit here refers to the total amount of credit in the banking system to the private sector. In the balance sheet of the banking system, fund appears in the liability side, while credit is the most important part of the asset side, so some researchers believe that credit index can also be used to measure the liquidity excess. Credit and fund are two ways to measure the liquidity excess just as they are two sides of the same coin. Borio \& Lowe [4] was the first to use the index to study the relationship between credit expansion and asset prices. They believe that the value can reflect the cumulative effect of credit expansion better than the simple credit growth rate. Gouteron \& Szpiro [10] also used the Credit/GDP index to measure the excess liquidity besides M/GDP and interest rates.

\subsection{Price}

The price index to measure the excess liquidity is based on interest rate. As the price and quantity of money supply are related to each other, the understanding of excess liquidity can be interpreted from both the quantity of 
money and the price. The amount of excess liquidity is generally measured in equilibrium or GDP, while its price scale is generally measured in the natural interest rate or the Taylor rule interest rate. If the real interest rate is below the natural rate or the Taylor rule, it suggests that monetary policy is too loose, which will stimulate excessive credit expansion and lead to excess liquidity.

Giese and Tuxen [9] used both the M/GDP index and the Credit/GDP index to study currency liquidity in 6 developed countries such as the United States and the Great Britain. They also used interest rates to carry out a more complete analysis with Taylor rule interest rate as reference. Gouteron \& Szpiro [10] also used the interest rate index to measure the excess liquidity in the sample countries besides M/GDP and Credit/GDP, with the natural interest rate as reference, which represents the equilibrium interest rate when there is no money in the economy. As the natural interest rate is not observable, Gouteron \& Szpiro [10] estimated the natural rate based on long-term economic growth rate, which is regarded as constant in the sample period.

At present, there is no literature using price index only to measure the excess liquidity. Usually this index is adopted to verify the findings as a complement to other quantitative methods. However, from the results of two researches mentioned above, the excess liquidities measured in the price index and in the quantity index are consistent. This can be verified from their data diagram.

\subsection{Comparison of Various Indexes}

The comparison of the advantages and disadvantages of each index is mainly made from the theoretical accuracy and the robustness of the measurement. The advantage of money gap lies in simple calculation, while its disadvantage is that the robustness is weak. No matter whether it is the nominal money gap or the real money gap, they are more sensitive to the choice of the base period. Different base selection will lead to different results. In addition, the calculation results of the money gap are also highly dependent on the equilibrium inflation rate, the trend of currency circulation velocity and the estimation of potential output. Gouteron \& Szpiro [10] pointed out some problems in the application of the index of money gap. They maintained that base period choice has great randomness, so they warned that the computational interpretation of the results needs to be cautious. This method of calculating money gap is applied widely, extending from empirical study to the normative research. However, they think it needs more research whether this approach is reasonable or not.

The index of money excess compensates for the weakness of money gap, and it avoids both the base period choice and the assumptions on the output gap and the velocity of money circulation. However, this index also has its own problems. The key to estimating the excess of money lies in the estimation of money demand function. If the demand function is unstable, the application of this method will be limited.

From the previous empirical study, we can see that the M/GDP index is the most widely used of various kinds of measures of money liquidity. As with the index of money excess, there is no choice of base in M/GDP index.
Because $\mathrm{M}$ is the total amount of money supply, the index also includes the cumulative effect of monetary expansion. It can be seen from the existing research results that money gap and money excess indexes are often used to study the relationship between inflation and currency liquidity [18] while the M/GDP or the interest rate index are often used to study the relationship between asset prices and liquidity excess [2,10,19]. In addition, as the M/GDP index is the actual value, it can be directly applied in calculating the liquidity excess.

\subsection{Choice of Indexes}

From the perspective of Chinese economic practice, the economic significance of the rising ratio of M2/GDP lies in the fact that the income elasticity of China's public money demand is greater than 1 . With the reform and opening up of the market, degree of monetization in trading continues to deepen in China. For example, some of the commodities in the planned economy belong to the governmental free supplies or low-cost supply, but after the reform they should be transacted according to the market price, from needing no money or a small amount of money to needing more money, and those that did not enter the transactions in the past enter the trading areas now. Therefore, the public demand for monetary transactions continues to rise. The degree of monetization in economic life has been increasing, resulting in rising demand for money, reflected in the M2/GDP index. In other words, economic monetization increased the public's demand for money and their transaction motivation, resulting in a long-term rise in the level of M2/GDP.

In developing countries like China, their economic activities can be divided into two parts: the monetary part and the non - monetary part. Generally speaking, the monetary part of the transaction is achieved in the market, while the non - monetary part, to a certain extent, is connected with the self - sufficiency economy of the barter exchange. With the economic reform, the monetary part of the transaction in China is growing, which is reflected in the following aspects: firstly, by increasing the income of residents and corporate profits, the transaction demand of residents and businesses has increased; Secondly, through the rural contract responsibility system, farmers enter the market, with the original self-sufficiency of agricultural products trading gradually transformed into the agricultural product market, increasing the share of currency transactions; Thirdly, by developing other economic composition beyond the public ownership, the supply of production materials and consumer products market has been expanded. When citizens' income grows ceaselessly, market capacity continues to expand, and currency's trading continues to increase; Fourthly, the production factors market is gradually opening up. With the continuous deepening of the reform, the securities market which had been regarded as heretical, the real estate market and the labor market have been gradually opening up. The introduction of these markets can be regarded as the generalized monetization, because money in the original meaning of the monetization is used as a medium of exchange, while in the capital market, especially in the stock market and real estate market, money plays a role in the circulation as a means of wealth. 
The first three factors have been more stable, but the fourth is currently in full swing in China, with a more rapid growth of the general circulation of money compared to the rapid growth of GDP. Obviously, Marshall $\mathrm{K}$ can reveal the liquidity abnormality in China more clearly.

Based on the above analysis, in the study of the impact of liquidity excess on the future market, it is more appropriate for this article to choose Marshall $\mathrm{K}$ value, M2/GDP, as a measure of liquidity excess.

\section{Measurement of Liquidity Excess}

The indexes in the preceding discussion can only roughly reflect the liquidity situation, but how can we measure the degree of liquidity excess? We compute the Marshall K value (M2 / GDP) as a measure of liquidity. Of course, we can also compute M2 growth rate of the nominal GDP growth rate as the measurement of liquidity. In fact, economic meaning is basically the same. The Marshall $\mathrm{K}$ value has the superiority of being always positive in econometric modeling, so this article chooses Marshall $\mathrm{K}$ value as the foundation of measurement. In order to increase the frequency of samples, we compute monthly Marshall K value in the sample period, that is, we use $\mathrm{m} 2$ / nominal GDP in order to capture the mobility of higher frequency changes. We select monthly frequency as sample index, in which approximate data of monthly GDP is obtained by the interpolation of the quarterly GDP data. (The interpolation may have the weakness of losing real volatility.).

In measuring liquidity excess, we use the index of money gap as a measure of the degree of liquidity excess, that is, excess liquidity, abbreviated (EL), is obtained by calculating the monthly Marshall $\mathrm{K}$ value in the sample period (such as m2 / GDP) and the deviation value of the long-term trend after the HP filter, and then subtracting the statistical average deviation values (or median) of all the samples. The calculation formula is as follows:

$$
E L=\operatorname{Min}\left\{\begin{array}{l}
\sum_{t=1}^{T}\left(K_{t}-\text { Ktrend }_{t}\right)^{2} \\
+\theta \sum_{t=2}^{T-1}\left(\begin{array}{l}
\left(K_{t+1}-\text { Ktrend }_{t}\right) \\
-\left(K_{t}-\text { Krend }_{t-1}\right)
\end{array}\right)^{2}
\end{array}\right\} .
$$

In the formula, $\theta=14400$

$$
E L_{t}=K_{t}-\text { Ktrend }_{t}
$$

\section{An Empirical Analysis of the Influence of Excess Liquidity on Copper Price}

\subsection{The Influence Factors of Copper Prices}

As a general merchandise, copper price fluctuation is mainly decided by supply and demand, the basic global economy, the changes in development trend of copper industry, production costs, related commodity prices, the
US dollar trend and other factors. The following will introduce the trend of copper prices and various influence factors in detail before identifying the influence of excess liquidity on copper prices.

\subsubsection{Supply and Demand}

It can be said that supply and demand is the most fundamental factor in determining the price, and the effects of other factors on the price of copper are directly or indirectly realized by affecting supply and demand. According to the fundamental microeconomic theories, under the condition of market economy, the price of a commodity is determined by the relationship between supply and demand. When the supply of a commodity is greater than the demand, the price falls; when the demand is greater than the supply, the price will rise. Price is a direct reflection of the relationship between supply and demand and the change of supply and demand. Copper price decision is no exception. The "general price" of copper, determined by supply and demand, depends on whether the supply or demand is the dominant factor. When demand declines and supply increases, copper prices will decline; when demand rises and supply decreases, the price of copper will rise. If the demand and supply changes in the same direction, that is, both increase or decrease at the same time, the two forces can be offset, the direction of price changes in the same direction of the larger forces.

Supply is equal to the output plus stock and it is affected by inventory, production in the period, production cost (exploration input, processing fees, copper mine development), the application of new technology, the producers' expectation of economic fundamentals, the government's industrial policy, import and export policies, business cycles and so on.

\subsubsection{Changes in Copper Industry}

The prospect of copper industry is directly related to copper consumption, which affects the price of copper. Consumption is a direct factor affecting prices while the development of copper industry is an important factor affecting the consumption. For example, in the 1990s in developed countries, pipelines in the construction industry increased the demand for copper, so the construction industry became one of the largest industries in copper consumption, thus contributing to the rise in the international price of copper in the middle of the 1990s. In the U.S. housing construction has become one of the factors affecting the price of copper. Since 2003, the development of China's real estate greatly promotes the growth in copper consumption, thus becoming one of the supporting factors in the rising copper price. In the automotive industry, manufacturers are promoting the use of aluminum instead of copper to reduce weight, reducing the amount of copper in the industry. In addition, with the rapid development of science and technology, the application of copper continues to expand, and copper has begun to play a role in medicine, biology, superconductivity, environmental protection and other fields. These changes will affect the copper prices to varying degrees. 


\subsubsection{The Dollar Exchange Rate}

Some factors which may be unrelated to supply and demand will also affect changes in copper prices, including foreign exchange market. The dollar exchange rate has effects on the price of copper, mainly because copper transactions are generally priced in dollars in the international markets. The depreciation of the dollar to a certain extent will make the copper consumption increase. According to past experience, the exchange rate changes will lead to the short term fluctuations in the price of copper, only with the influence on the degree of rise and fall, but it cannot change the basic pattern of the copper market.

\subsubsection{Stock Market}

The impact of the stock market on the price of copper can be both positive and negative. The positive relationship between the stock market and the price of copper is reflected in three aspects: firstly, the stock market is a barometer of the economy. The cycle of the stock market is not only related to the economic cycle, but also a leading indicator of the economic cycle. The supply and demand of copper is closely related to the macro economy. Therefore, the stock market indirectly affects the price of copper. Secondly, the stock market affects the copper price by influencing the expectation of investors. For example, when the stock market falls, the decline will hit investor confidence, which will have a chain reaction on the futures market. The stock market boom will also lead to the popularity of futures market. Thirdly, the mineral stock price trend sometimes keeps ahead of metal market. Therefore, the overall operation of the copper company stock price trends can help to predict the future trend of copper prices. The reverse relationship between the stock market and the price of copper is mainly reflected in the cross market liquidity. In the case of excess liquidity, the stock market crash may lead to a large number of profit driven capital flowing into commodity market to push prices higher. Therefore, the relationship between stock price and copper price depends on the specific circumstances.

\subsubsection{Crude Oil Price Trend}

Copper, aluminum, crude oil and other commodities all belong to the same energy commodities, and they are nonrenewable. In industrial production and industrial consumption, they occupy an important position. Common industrial attributes make their consumption, production and circulation closely linked. Crude oil is an important commodity in the world economy, and the rise or fall of the price of crude oil, to some extent, indicates a change in the price of other commodities.

\subsubsection{The Involvement of Fund}

The involvement of fund affects the price of copper. In fact, the trend of the copper market can be reflected in the periodical capital positions. A very important indicator in the analysis of the change of capital positions is the noncommercial net positions, the difference between the speculative long positions and short positions, also known as net speculative long positions. Holding net speculative long positions will lead to rising copper prices, and will become the main reason for the price rise in some cases.

\subsection{Variable Determination and Data Processing}

This chapter is mainly to study the impact of the excess liquidity on copper price, so copper is used as explanatory variables. In order to study the impacts of excess liquidity surplus on copper price changes more clearly, here we choose the copper futures price volatility as surrogate markers of explanatory variables. Volatility is generally defined as the magnitude or frequency of price changes, generally expressed as the standard deviation of price changes:

$$
S T D V=\left(\frac{1}{N} \sum_{i=1}^{N}\left[P_{i}-E\left(P_{i}\right)\right]^{2}\right)^{\frac{1}{2}} .
$$

In the formula, STDEV represents volatility, that is, the standard deviation of the price, $\mathrm{N}$ the sample size, $\mathrm{Pi}$ the sample price, E (Pi) the sample average price. This formula provides a measure of price fluctuation in a period of time. But due to the difficulty of obtaining the daily interval trading data, the formula cannot calculate the daily price fluctuations, so it is only a theoretical formula. Here the GK equation estimators are used to calculate the volatility index in Shanghai copper futures market. Schwert (1990) showed that this estimation method is better than the GARCH model estimation. The formula is:

$$
A V O L_{t}=\left\{\begin{array}{l}
\left(0.5 \times\left[\ln \left(\frac{P_{t H}}{P_{t L}}\right)\right]\right)^{2} \\
-(2 \ln 2-1) \times\left[\ln \left(\frac{P_{t O}}{P_{t C}}\right)\right]^{2}
\end{array}\right\}^{\frac{1}{2}} .
$$

In the formula, AVOLt represents the price volatility, PTH, PTL, PTO and PTC represent respectively the highest price, the lowest price, opening price and closing price in the t period (month) contract. The data is taken from Shanghai Futures Exchange website and Hongye Futures Brokerage Company.

Here EL (excess liquidity) is obtained from the calculation method mentioned above. In practice, the factors which affect the explanation variables are often more than one, and a single-element regression model is difficult to satisfy the classical assumption, as the omission of important variables leads to the error term which is not in conformity with the zero conditional assumption, resulting in endogenous problems, and deviate and inconsistent estimated coefficients. So in addition to the liquidity, we also need to control other factors influencing copper price, forming a multivariate regression model.

According to the analysis above, there are many factors affecting the price of copper, such as macro economic situation, supply and demand, the dollar exchange rate and so on. Based on the copper pricing model provided in the existing literature on mining economics, there are three variables: the US dollar to RMB exchange rate index, the industrial production and the stock. However, the relationship between supply and demand is the core factor 
of commodity prices, and inventory quantity directly reflects the comprehensive status of supply and demand. When the inventory increase, the supply is greater than demand and prices fall; when inventory reduces, the demand picks up and prices rise. Therefore, inventory as a variable is added. The quality of other macroeconomic conditions tends to reflect the economic boom and, thereby affects industrial production and demand, so the influence of macroeconomic trend on the price of copper cannot be ignored. Based on financial attributes of commodities, capital flow across the markets will cause certain correlation between stock market and commodity market. Besides, both industrial production scale and output of copper also have an impact on the copper price. Therefore, we will include the industrial output (GDP) as a control variable, whose data is taken from the National Bureau of Statistics. Since international commodities tend to be priced in dollars, the dollar exchange rate will have a certain impact on the price of copper. With the appreciation of the dollar, there is a fall in copper prices. In the case of depreciation of the dollar, copper prices rise. So the dollar index (Nominal generalized dollar index announced on the website of the U.S. Federal Bureau of Statistics) is included. Other factors include the fund's net position and net position in the business. However, because of the serious multicollinearity among three factors: copper stocks, net fund positions and net business positions (embodied in the screening and optimization of the model), along with Eviews5.0 testdrop test, finally only copper inventory is retained, whose data is taken from Shanghai Futures Exchange and Hongye Futures Brokerage Company.

Because each future contract will cease to exist once it expires, the future price has the features of continuity different from the stock price. Therefore, this paper selected data according to the following method. Copper future has a total of 12 contracts of delivery every year from January to December. Since the trading is usually more active when close to the delivery month, the data of the third month lagged behind each contract delivery month was selected as sample, and so on. For example, the data of January 2007 is taken from April 2007 delivery contract, the data of February 2007 from May 2007 delivery contract. The final selection of future data is not only characterized by continuity, but each date to select data is controlled in three months before the settlement, when the future price and spot price are close and the result is more stable.

According to the result of the excess liquidity, this paper chooses one period (2006.3-2008.5) as sample time window, all together 27 observations for each sequence. Here the original data sequence is not directly employed to carry on the regression analysis. Instead, log processing of the variables is made in advance, establishing logarithmic model. There are many advantages in using logarithm function form rather than the simple linear model: variable measure unit is no longer important; the probability of heteroscedasticity in the model has been reduced; logarithmic model usually narrows down the range of variables, making the estimates less sensitive to abnormal values; the model is more likely to conform to the classical regression model assumptions.

\subsection{Multiple Regression Analysis}

First we use $\mathrm{EL}_{\mathrm{t}}$ as the benchmark index measuring liquidity to analyze the impact of liquidity on the price of copper.

$$
\begin{aligned}
\text { AVOL }_{t}= & \beta_{0}+\beta_{1} E L_{t}+\beta_{2} \text { totalstock }_{t} \\
& +\beta_{3} i_{t}+\beta_{4} \text { dollar }_{t}+\beta_{5} i p_{t}+\varepsilon_{t} .
\end{aligned}
$$

In the formula, AVOL represents the copper future price volatility in Shanghai Futures Exchange, "totalstock" the total copper inventories of three world's large Copper Futures Exchange, ip the Chinese GDP growth rate, dollar the exchange rate of the RMB against the U.S. dollar, isp the Shanghai stock index. According to the analysis made above, we made a log processing of the explanatory variables and all of the control variables in advance. Of course, AVOLt is on a logarithmic scale in calculation, so here is its original value.

$$
\begin{aligned}
\text { AVOL }_{t}= & \beta_{0}+\beta_{1} \ln E L_{t}+\beta_{2} \ln \text { totalstock }_{t} \\
& +\beta_{3} \ln i p_{t}+\beta_{4} \ln \text { dollar }_{t}+\beta_{5} \ln i s p_{t}+\varepsilon_{t} .
\end{aligned}
$$

The estimated results are as follows (the letter $\mathrm{d}$ before the name of the variable means being processed by the first order difference):

$$
\begin{aligned}
& d A V O L_{t} \\
&=-0.735+1.109 d \ln E L_{t}-0.051 \ln \text { totalstock }_{t} \\
&+0.294 \ln i p_{t}-2.017 d \ln \text { dollar }_{t}-0.538 d \ln i s p_{t} \\
&\left(\begin{array}{l}
0.2695 \\
3.0926
\end{array}\right)\left(\begin{array}{l}
0.0741 \\
-2.0472
\end{array}\right)\left(\begin{array}{l}
0.5015 \\
0.6867
\end{array}\right)\left(\begin{array}{l}
1.2637 \\
-2.9462
\end{array}\right)\left(\begin{array}{l}
1.2473 \\
-3.1542
\end{array}\right) \\
& R^{2}=0.804 \text { Adjusted }-R^{2}=0.792 \text { D.W }=1.409 F=6.7 .
\end{aligned}
$$

Below each estimated coefficient in parentheses are standard errors and $\mathrm{t}$ statistics, associated probability of each coefficient t-statistic is 0 . 0009, 0.1082, 0.3807, $0.0013,0.1573$, and the impact of the M2 growth rate and the dollar index change on fluctuations of copper prices is significant at $1 \%$. When M2 increased, fluctuations in copper prices rise. When the dollar rises, copper prices decline, because the dollar is the price currency of copper price, and its effect should be negative; inventory is significant at $13 \%$, and it has negative effects on copper prices, which is consistent with economic theory, that is, the more stock means excess supply, leading to the price decline. GDP growth rate and SSE Composite Index have no significant influence on the fluctuations of copper prices (by comparison, we find regression model without these two factors is inferior to the model proposed in this article. Besides, these two factors have significant effect on copper price in the economic sense. Therefore, they are still retained.).

Model fitting $\mathrm{R}^{2}=0.807$ (adjusted $\mathrm{R}^{2}=0$. 792), indicating that the combination of the money supply growth rate, copper inventories and GDP growth rate, the exchange rate of RMB against the U.S. dollar and Shanghai stock composite index can explain $80.7 \%$ of the fluctuations of copper prices. The concomitant probability of F test was 0.000283 , which showed that the regression equation was significant at $1 \%$. D.W=l. 409 , for $n=38$, 
$\mathrm{k}=5$, critical value at $1 \%$ is $d_{u}=1.58, d_{l}=1.03$, suggesting that the residual sequence does not have the autocorrelation in the sequence.

Model fitting is not very high, suggesting that there are some variables which are difficult to control, and the uncontrolled variables affect the fluctuations of copper price. However, we here use a first-order difference method, so it can be said that those omitted variables which do not change with the time do not cause the endogeneity in the model after the first order difference.

In order to further describe the nature of the relationship between fuel oil price fluctuation and excess liquidity, we use the unit root test, cointegration and VECM model to conduct in-depth analysis with El as a proxy for liquidity.

\section{Conclusion}

Over the past few years, the world's major economies have generally implemented the ultra-low interest rate policy. In order to restore economic growth, on January 3 2001 the Fed started to cut interest rates, followed by the European Central Bank in the same year. In order to stimulate economic recovery, the Bank of Japan carried out ultra-loose monetary policy for up to five years. Three largest economies in the world implemented loose monetary policy for a long time, which led to unprecedented growth in the major currency liquidity. According to preliminary estimates, the global liquidity level of short-term monetary growth rate minus nominal GDP growth rate has increased by 60\% since 1996 . Excess liquidity resulted in an unprecedented rise in global asset prices, and the proliferation of liquidity promoted the asset price revaluation, covering the stock market, commodity market, real estate, Shi Bo, gold and art investment market, huge amounts of money flowing into the capital market. In such a situation, there appeared a super bull market for the copper price.

The excess liquidity and the reversal of the movement was widely believed to be the main factors leading to inflation and asset price volatility in developed countries. This paper contributes to the literature on the information that it is also the case in developing countries like China. In fact, emerging economies are experiencing more liquidity abnormality than developed countries, and economic significances of the impact of the liquidity is even larger in developing countries.

To measure the degree of the liquidity excess, we propose a measure which is based on M2/GDP and which is especially applicable to developing countries. We also improve the existing calculation of volatility by making a log processing of the explanatory variables and all of the control variables in advance. Through multiple regression analysis, Grainger causality test, Cointegration test, vector error correction model and impulse response function, it is found that liquidity excess accounts for the changes of copper prices in the future market. We conclude that the economic impact of the liquidity excess is significantly larger in developing countries like China where currency abnormality is more prominent.

\section{Acknowledgements}

The thanks should go to Jiangsu Education Committee for the Grant of Graduate Students Innovation Program (KYZZ16_0448).

\section{References}

[1] Bruggeman, A., 2007. Can excess liquidity signal an asset price boom? Working Paper. No. 117. National Bank of Belgium. http://www.nbb.be/doc/oc/repec/reswpp/wp117en.pdf.

[2] Baks, K., Kramer, C., 1999. Global liquidity and asset prices: Measurement, implications, and spillovers. IMF Working Paper 99/168.

[3] Belke A., Setzer, R., Orth, W., 2009. Global excess liquidity does it matter for house and stock prices on a global scale. Journal of Financial Transformation. 24: 145-154.

[4] Borio, C., Lowe, P., 2002. Asset prices, financial and monetary stability: Exploring the nexus. BIS Working Papers, 1-39.

[5] Xia B., Chen, D. F., 2007. China’s liquidity report [EB/OL]. http: / /data. stock. hexun. com/2349711. Shtml, 07 -09.

[6] European Central Bank. 2001. Monthly Bulletin [EB/OL]. http://www.ecb.int/home/html/index.en.html.

[7] Engle R.F., Granger, J. C. W., 1987. Cointegration and error correction: Representation, estimation and testing [J], Econometrica, 55, 251-276.

[8] Ferguson, R.S. Jr., 2007. Asset prices and monetary liquidity. To the Seventh Deutsche Bundesbank Spring Conference, Berlin, Germany.

[9] Giese, J. V., Tuxen, C. K., 2007. Global liquidity and asset prices in a Cointegrated VAR. Nuffield College, University of Oxford, and Department of Economics, Copenhagen University. 1-28.

[10] Gouteron, S., Szpiro, D., 2005. Excess monetary liquidity and asset prices. Working Paper. Banque de France. 1-53.

[11] Ha J. M., 2007. The Analysis of the effects of Chinese citizens' direct investment in overseas stock market. Southwest Finance. 10: 43-50.

[12] Jin C.X., Wang, M., Wang, J. Y., 2010. Excess liquidity and asset price inflation-Based on econometric analysis of VEC, Taxation and Economy. 4:1-7.

[13] Johansen, S., 1988. Statistical analysis of cointegration vectors. Journal of Economic Dynamics and Control. 12: 231-254.

[14] Johansen, S., Juselius, K., 1990. Maximum likelihood estimation and inference on cointegration-With applications to the demand for money. Oxford Bulletin of Economics \& Statistics. 52: 169-210.

[15] Li J. J., 2006. Estimating theory and approach for the nonobserved money fund in China. The Journal of Quantitative \& Technical Economics. 7:58-68.

[16] Liu C.H., Zhang, X., 2007. The prosperity expectation, liquidity changes and asset prices. Finance Research. 6:86-99.

[17] OECD. 2001. Handbook for Measurement of the Non-observed Economy, Second Draft.

[18] Polleit. T., Gerdesmeier, D., 2005. Measures of excess liquidity. http: //www. Hfb.de/Dateien/.

[19] Rüffer, R., Stracca, L., 2006. What is global excess liquidity, and does it matter?. ECB Working Paper. 1-50.

[20] Sun J. H., 2006. The analysis of excess liquidity of commercial banks from the perspective of macroeconomics. Financial Science. 7: 83-99.

[21] Sebastian B., 2007. Global liquidity glut and asset price inflation. Deutsche Bank Research.

[22] Tian S.H., 2007. Exploration of the causes of excess liquidity of Chinese commercial banks. Economic Issues in China. 5: 38-50.

[23] Tian B.P., Fang L., 2010. Factors analysis on liquidity surplus and a rise of Chinese stock markets. Systems Engineering-Theory \& Practice. 2:277-286.

[24] Giese V. J., Tuxen, C. K., 2007. Global liquidity and asset prices in a Co-integrated VAR [EB/OL]. http://www.economics.ox.ac.uk/hendryconference/Papaers/Giese_ DFHVol.pdf.

[25] White, W., 2006. Is price stability enough? BIS Working Paper. 205. 
[26] Xu D. L., Ye, S. B., 2008. Theoretical and empirical study on measuring methods of China's excess liquidity. The Journal of Quantitative \& Technical Economics. 3:3-16.

[27] Xu T., Dong, Y. X., 2010. Excess monetary liquidity, noise trading and asset price volatility. On Economic Problems. 2:4-10.
[28] Yu Y.D., 2007. Understanding excess liquidity. International Economic Review. 7: 12-25.

[29] Zhang C., 2009. Excess liquidity, inflation and Yuan appreciation: What can China learn from recent history?. The World Economy. 32: 998-1018. 